\title{
TED-Ed web-based blended learning to support teaching: An action research project
}

\author{
Russell, Douglas ${ }^{a}$ \\ ${ }^{a}$ Departments of Education and Psychology, Middlesex University Dubai, U.A.E
}

\begin{abstract}
The use of video material to support the pedagogical shift to blended learning has begun being utilised in traditional campus based universities. This student centred approach has supported higher education practitioners in adapting their practice to better meet the diverse student populations entering university. An action research project utilizing TED-Ed to introduce out of class, student centred learning was conducted by a Dubai based lecturer. A class of 65 students enrolled in a second year Psychology module completed between one to three online activities and answered a qualitative survey sharing their opinions towards completing the tasks. The results showed that blended learning could be effectively used as a teaching tool to support practice in a 'traditional' university with a focus on the lecture/seminar approach. Lecturers seeking to extend their students' learning into out of class environments should consider the use of TED-Ed as a suitable tool for not only achieving this but also supporting the needs of $21^{\text {st }}$ century tertiary students.
\end{abstract}

Keywords: TED-Ed; Blended learning; university; student learning; learning environment; action research. 


\section{Introduction.}

\subsection{The Problem}

Within the first week of class, whilst discussing the module handbook, students were asked if they had any questions. Instantly a confident young woman asked, 'When are the seminars and workshops?' to which my answer was 'There aren't any'. The first piece in the puzzle that was my problem had emerged. PSY2014 focuses solely on theories with the only workshops occurring as support for the first summative assignment. The need to cover so much theory leaves little room for student-centred pedagogical practice or any form of interactive learning. My research with a colleague regarding students' learning strategies identified a lack of reading, surface approaches to learning and a lack of out of class studying as major contributors to the lack of understanding within modules across the sample studied. As the second puzzle piece making up the issue I was facing this one was closest to my heart. I wanted my practice to give students the opportunity to learn what they felt was personally relevant, and of interest to them, coming back more motivated as the year progressed. Finally, in the most recent board of studies for Psychology, students had requested more videos, which ironically the student representative had found humourous due to the already frequent use of video within the class to help consolidate theory. I realized however on reflection that despite the use of videos in the class, the students had not identified this as a learning tool.

\subsection{The Solution}

As a result of the modern knowledge society, fundamental shifts in the role of the lecturer and pedagogy to a learner centred environment is essential (Hoic-Bozic, Mornar, \& Boticki, 2009). The use of e-learning is a suitable way of shifting the focus of the learning environment, making the students' role more active (Garrison, 2011). Video material has been used for many decades to support the motivation and learning of students in higher education (Chin, 2004), and has been recently suggested as one of many additional learning resources which can be utilised by lecturers to foster deep approaches to learning (Azer, Guerrero \& Walsh, 2013). Indeed, videos used in class can support the link between theory and real life (Seidel, Blomberg, \& Renkl, 2013) in developing understanding of abstract ideas (Eick \& King Jr., 2012), and encourage learning outside the normal teaching environment (Mitra, Lewin-Jones, Barrett, \& Williamson, 2010). Students currently entering university are seen as digital natives (Prensky, 2005) and benefit when digital technology is incorporated in the learning environment, with younger students reporting greater enjoyment when video is used as a teaching tool in class (Fee \& Budde-Sung, 2014). The use of blended learning, an approach which utilises a combination of face to face teaching as well as online learning has been identified as better than either of these approaches used in isolation (Mehaffy, 2012). This pedagogical approach has the power to 
promote higher-order thinking skills and foster critical reflection (Garrison, 2011), both of which are identified as key elements in using a deep approach to learning (Biggs \& Tang, 2011). In contrast with the expository, didactic approaches of typical face to face learning, blended learning typically engages students in an active learning process (Means, Toyama, Murphy, \& Baki, 2013). This student centred approach, which bases its pedagogy within the framework of constructivist principles (Norberg, Dziuban, \& Moskal, 2011) has been found to encourage students to be more autonomous, more critical and use deep learning approaches (Baeten, Kyndt, Struyven, \& Dochy, 2010; Carper, \& Nicholson, 2011; Slevin, 2008; Vogel-Walcutt, Gebrim, Bowers, 2011). Although there are challenges associated with integrating online education in to the current HE system (King \& Alperstein, 2015), as a means to solving the many problems I was facing within PSY2014 a video based blended learning approach seemed to be appropriate. TED-Ed (TED-Ed, n.d.), launched in 2012, allows teachers to extend learning beyond a lecture format (Education Letter, 2012). The website allows anyone to choose a video online and create multiple choice and open ended questions to support learning regarding the videos topic. As a constructivist teaching tool the facilitator can then create a paragraph asking students to 'dig deeper' and also create discussions for students to synthesise material from the video, additional readings and class, as well as critically analyse different points of views from classmates. Mehaffy (2012) discusses how these changes identified within the HE system are going to lead faculty to be more 'guides on the side' in comparison to the old adage of 'sage on the stage'. He goes on to note how TED-Ed is a more than suitable tool for supporting teaching practice in a new model of education which supports students to learn what they want, when they want, at the pace they want.

\section{Methodology}

\subsection{Design}

This action research study takes on a phenomenological design, exploring qualitatively the effectiveness of TED-Ed as a teaching tool.

\subsection{Participants}

Students (N=66) taking part in PSY2014; Developmental Psychology (2015-2016) were opportunistically sampled from the Dubai branch campus of a British university. The sample ranged in age from 19 to 24 and came predomintantly from Asian and Arab backgrounds. 


\subsection{Procedure}

In weeks nine, ten and eleven students completed a TED-Ed activity designed to support learning for previous topics taught in semester one. In Week 12 students were given a qualitative open ended questionnaire seeking information regarding study strategies utilized while completing the TED-Ed activities, as well as their general feelings in its use within the module to support learning. TED-Ed web-based blended learning to support teaching: An action research project

\subsection{Materials}

A single 'in the moment' open-ended question at the end of each TED-Ed activity asked students how they felt about the task in relation to their learning, typically phrased as 'Write down how you found the experience of completing a Ted-Ed lesson.'

A qualitative open ended questionnaire was used as a second measure of students perceptions towards the use of TED-Ed as a blended learning tool, to identify reasons for choosing to complete the TED-Ed activities, how the video activities assisted in learning content and skills and finally whether students felt TED-Ed activities were a suitable extension of lectures in light of the lack of seminars/workshops.

\subsection{Analysis}

To analyse the effectiveness of using TED-Ed as a blended learning teaching tool to support deep approaches to learning, as well as benefits and changes to learning strategies from a student perspective, answers from the open ended questionnaire were read and coded using thematic analysis.

\section{Results.}

\subsection{Thematic Analysis}

The themes that emerged from the students' responses encompassed four overarching themes: Multiple Perspectives, Teaching Environment, Construction and Application, and Academic Skills. Table 1.summarises major themes and subthemes. 
Table 1.Themes identified from end of activity questions and summative interview.

\begin{tabular}{ll}
\hline Themes & Subthemes \\
\hline (1) Multiple Perspectives & i. Deeper Understanding \\
& ii. Others perspectives \\
& iii. Lecturers viewpoint \\
& iv. Appreciating Questions \\
\hline (2) Teaching Environment & i. Own pace \\
& ii. In-class Discussion \\
& iii. Combining Environments \\
\hline (3) Construction and Application & i. Visual Learning \\
& ii. Applying Knowledge \\
& iii. Going deeper \\
\hline (4) Academic Skills & i. Synthesising Material \\
& ii. Critical Analysis \\
iii. Referencing & iv. Viewed as Revision \\
& v. Information Literacy \\
\hline & \\
& \\
&
\end{tabular}

The theme of Multiple Perspectives came about as a result of students (approximately 40\%) identifying their own understanding from a personal perspective as a result of completing the TED-Ed activities. This can be seen in the following two verbatim quotes from participants 'To gain a better understanding of what was being taught in class,' and '[It] helps to get a clearer idea about the topic'.

Alongside this, an understanding of their classmates' perspectives through the discussion threads, or noting a desire to put aside some in-class time to discuss their different thoughts and feelings regarding the content of each activity was also evident through quotes such as 'It would be beneficial to know different views and opinions on different topics', and 'It would be beneficial, as different perspectives to the same topic can be discussed.'

The second theme emerged around the notion of 'Teaching Environment'. This theme centred on the idea that students very much enjoyed the independence and autonomy related to the TED-Ed activities as seen in the following quote: 'I prefer TED-Ed activities as I am on my own pace...', 'I prefer TED-Ed activities as you can do it at a time that is comfortable for you as well as at your own pace'. 
However, the students were eager to have these combined with in-class seminars throughout the year, or at the very least have discussions in class to support the out of class blended activities they were completing. Quotes such as 'I like TED-Ed activities but if I have doubts at that moment I prefer my lecturers to help me then and there' and 'The inclass seminars and the TED-Ed video could be mixed. We could get the best of both worlds, 'support these findings.

The third theme that was identified through analysis of the data revolved around that of 'Construction and Application'. Approximately a third of the students made it clear that their engagement and ability to independently construct a deep understanding through the TED-Ed activities were the result of a visual learning style. 'As I am more of a visual learner, I found the videos very interesting and stimulating as it kept my attention.'

Moreover, approximately half the students felt that their ability to construct the knowledge and material around a real life situation and being able to apply the learning to case studies in the videos supported better understanding of the material at hand. One student noted that 'They [TED-Ed activities] gave me a more practical sense of the topics discussed, they encouraged my critical thinking skills and deeper reading skills.'

A fourth theme of 'Academic Skills' emerged from the data whereby students made it clear that the TED-Ed activities had increased their independence, awareness and skills in synthesizing literature, going beyond the suggested material in the module handbook, thinking critically, and the use of discussion to argue viewpoints. An example quote identifying the use of independence was 'It was a kind of guide, [a] self-study tool'.

Some students however described skills which weren't related to deep approaches or extending their skills. For example 'I skimmed through articles to find answers to certain questions especially the discussion section. I thoroughly read the recommended texts' and 'The questions were useful since it was like a revision.'

\section{Discussion.}

The aim of the current study was to ascertain whether TED-Ed activities were an effective blended learning tool in supporting the use of deep learning approaches in a Psychology module largely lacking in student centred pedagogy. Students are assessed in this module via one piece of coursework; a developmental observation report and an exam at the end of the academic year. It is hoped that by completing the TED-Ed activities that students will have a more holistic understanding of the topics covered by the exam questions. The results of the present study clearly indicate that students enjoy and benefit from the use of video based, out of class activities. Constructivist approaches such as that used in the current intervention have been identified as a successful manner in which to foster deep learning 
approaches from students (Vogel-Walcutt et al., 2010). The findings of the current study show not only the use of higher order thinking skills but also a shift in the teaching environment from teacher-centred to student-centred, which has been identified as the most important pedagogical shift required in order to successfully use blended learning within one's teaching practice (Hoic-Bozic et al., 2009), and support students' use of deep approaches to learning. Results from the current study indicate that students clearly appreciate the visual aspect of using video material to support learning outside of the class. Mitra and colleagues (2010) discuss how the use of video material which supports the use of both visual and auditory processing results in better learning, engaging students in deep learning. Chen and Gilchrist (2012) extol the use of TED-Ed as a tool for creating a teaching environment which fosters deep approaches to learning, however noting that attention to the quality of the video and other learning material is an important consideration when creating activities. Learning approaches are dynamic and are interchangeably used in response to the learning environment presented to students (Azer et al., 2013). Thus, it is the responsibility of the lecturer to use video in a way which fosters reflection, synthesis and other higher order thinking, as opposed to presenting work which students see as revision. An additional pedagogical approach that is convergent with the use of blended learning is that of interactive learning (Means et al., 2013) whereby students' learning emerges as a result of interactions with each other and the lecturer (Cox, 2011). This approach is highly sought after by the students as they voiced a desire to utilise both online activities in their own time and space, but also to come back to class and discuss their opinions and thoughts, hear those of others and to clarify doubts. Previous studies focusing on student centred environments have shown that both student-lecturer and student-student interaction are both effective ways of developing sound understanding as well as support the incorporation of higher order thinking skills in to teaching activities (Baeten et al., 2010; Garrison, 2011). In order to better support the variety of students entering the HE system in the 21st century (Biggs \& Tang, 2011; Prensky, 2005) it is imperative that faculty are able to adjust their pedagogy. The current study is based on an intervention which acts as a pilot study in the ongoing professional development of one Dubai based lecturer, which indicates that TED-Ed has the potential to unlock a paradigmatic shift in teaching practice. The use of technology and blended learning to support students gives rise to boundless opportunities to develop tools which ensure effective teaching in Psychology, as well as other subject areas, through student centred teaching.

\section{References}

Azer, S. A., Guerrero, A. P. S., \& Walsh, A. (2013). Enhancing learning approaches: Practical tips for students and teachers. Medical Teacher, 35, 433-443. 
Baeten, M., Kyndt, E., Struyven, K., \& Dochy, F. (2010). Using student-centred learning environments to stimulate deep approaches to learning: Factors encouraging or discouraging their effectiveness. Educational Research Review, 5, 243-260.

Biggs, J., \& Tang, C. (2011) Teaching for Quality Learning at University (4th ed.). Berkshire, England: Open University Press, McGraw Hill Education.

Chen, H. L., \& Burns Gilchrist, S. (2013). Online access to higher education on YouTubeEDU. New Library World, 114(3/4), 99-109.

Chin, P. (2004). Using C\&IT to support teaching. London, U.K: Routledge Falmer

Cox, J. R. (2011). Enhancing student interactions with the instructor and content using penbased technology, YouTube videos, and virtual conferencing. Biochemistry and Molecular Biology Education, 39(1), 4-9.

Education Letter. (2012). TED-Ed Launches Groundbreaking Website with New Tools for Customized Learning. Available at: https://global-factivacom.ezproxy.mdx.ac.uk/ga/default.aspx (Accessed: 5/12/15)

Eick, C. J., \& King Jr., D. T. (2012). Nonscience majors' perceptions on the use of YouTube video to support learning in an integrated Science lecture. Journal of College Science Teaching, 42(1), 26-30.

Fee, A., \& Budde-Sung, A. E. K. (2014). Using video effectively in diverse classes: What students want. Journal of Management Education, 38(6), 843-874.

Garrison, D. R. (2011). E-Learning in the 21st Century: A Framework for Research and Practice. ( $2^{\text {nd }}$ ed.). London, U.K: Routledge, Taylor and Francis

Hoic-Bozic, N., Mornar, V., \& Boticki, I. (2009). A blended learning approach to course design and implementation. IEEE Transactions ion Education, 52(1), 19-30.

King, E., \& Alperstein, N. (2015). Best Practices in Online Program Development: Teaching and Learning in Higher Education. London, U.K: Routledge, Taylor and Francis

Means, B., Toyama, Y., Murphy, R., \& Baki, M. (2013). The effectiveness of online and blended learning: A meta-analysisof the empirical literature. Teachers College Record, $115,1-47$.

Mehaffy, G. L. (2012). Challenge and change. Educause Review, 47(5), 1-24.

Mitra, B., Lewin-Jones, J., Barrett, H., \& Williamson, S. (2010). The use of video to enable deep learning. Research in Post-Compulsory Education, 15(4), 405-414.

Norberg, A., Dziuban, C. D., \& Moskal, P. D. (2011) "A time- based blended learning model". On the Horizon, 19(3), 207-216.

Prensky, M. (2005). Listen to the Natives. Educational Leadership, 63, 8-13.

Seidel, T., Blonberg, G., \& Renkl, A. (2013). Instructional strategies for using video in teacher education. Teaching and Teacher Education, 34, 56-65.

Slevin, J. (2008). E-Learning and the transformation of social interaction in higher education. Learning, Media and Technology 33, 115-26. 
TED-Ed (n.d). TED-Ed Lessons worth sharing. Available at: http://ed.ted.com/about Vogel-Walcutt, J. J., Gebrim, J. B., Bowers, C., Carper, T. M., \& Nicholson, D. (2011). Cognitive load theory vs. constructivist approaches: Which best leads to efficient deep learning? Journal of Computer Assisted Learning, 27(2), 133-145. 